\title{
Políticas sociais de enfrentamento da pobreza na América Latina: uma análise comparada entre Brasil e Argentina
}

\section{Lauro Mattei}

Universidade Federal de Santa Catarina (UFSC)

Políticas sociais de enfrentamento da pobreza na América Latina: uma análise comparada entre Brasil e Argentina

Resumo: Desde a década de 1990 diversos países da América Latina estão adotando políticas públicas visando à redução da pobreza e da exclusão social, destacando-se os programas de transferência de renda que passaram a compor o núcleo central das ações governamentais em vários países. O objetivo do estudo é analisar comparativamente a evolução da pobreza no Brasil e na Argentina no início do século 21, bem como as políticas públicas em curso. Como instrumento de análise foram utilizados dados secundários relativos aos dois temas disponíveis em ambos os países. Concluiu-se que esses programas contribuíram decisivamente para reduzir os níveis de pobreza nos dois países, todavia a erradicação da pobreza necessita de uma maior articulação entre as diversas políticas sociais visando à construção e consolidação de um sistema de proteção social amplo.

Palavras-chave: Brasil. Argentina. Pobreza e exclusão social. Transferência de Renda.

Social Policies for Confronting Poverty in Latin America: a comparative analysis of Brazil and Argentina

Abstract: Since the 1990s various Latin American countries have adopted public polices to reduce poverty and social exclusion, highlighted by the income transfer programs that compose the central core of government actions in various countries. The objective of this study is to conduct a comparative analysis of the evolution of poverty in Brazil and Argentina in the early 21st century, as well as the public policies of the time. The analysis focused on secondary data about the two themes found in both countries. It concludes that these programs contribute decisively to reducing the levels of poverty in the two countries, yet emphasizes that the eradication of poverty requires greater articulation between the various social policies and emphasizes the need for the construction and consolidation of a broad social protection system.

Keywords: Brazil. Argentina. Poverty and social exclusion. Income Transfer. 


\section{Introdução}

A América Latina apresenta marcas históricas que remontam ao processo colonizador o qual, por vários séculos, destinou a esse espaço geográfico apenas a função de produção e suprimento de bens primários necessários ao atendimento dos interesses das metrópoles, em particular, a lusitana e a espanhola. Tal lógica colonizadora, além de formar e estabelecer uma estrutura socioeconômica voltada ao exterior deixou marcas econômicas e sociais ainda presentes, entre elas destacam-se: a pobreza, a concentração de renda e a exclusão social. Mesmo não sendo um fenômeno recente no continente latino-americano, a pobreza e a exclusão social tornaram-se mais amplas a partir das crises econômicas que afetaram a maioria dos países da América Latina nos anos de 1980 quando, além das deficiências estruturais do modelo de desenvolvimento socioeconômico regional, os problemas sociais se transformaram em obstáculos reais para a conformação de sociedades mais justas, igualitárias e democráticas.

A partir da década de 1990, a América Latina viveu um período de grandes mudanças especialmente na esfera econômica com a adoção de políticas comerciais liberalizantes, fazendo com que as exportações e as importações aumentassem generalizadamente. Segundo a ONU (2005), entre 1991 e 2000 o volume físico das exportações da região cresceu a uma taxa anual de 9,3\%, enquanto que as importações cresceram a taxas ainda mais elevadas. Entretanto, em muitos países o que se assistiu foi o crescimento de desequilíbrios na balança comercial, com impactos negativos sobre o nível de atividade econômica e sobre o balanço de pagamentos. Uma das consequências diretas do pequeno crescimento econômico regional, segundo a ONU (2005), foi a redução do nível de emprego com a contrapartida no aumento da informalidade. Este duplo movimento levou a uma redução do número de pessoas cobertas pelos programas de seguridade social, obrigando os governos a ampliarem os gastos públicos na esfera social. Em termos agregados, esses gastos subiram de 10\% do PIB, em 1990, para 13,8\%, em 2003 (ONU, 2005). Mesmo assim, para a CEPAL (2005)¹, o impacto desta expansão dos gastos é ainda incipiente, uma vez que em 2002 existiam 221 milhões de pessoas enquadradas como pobres, o que representava 44\% de toda a população do Continente. Deste total, aproximadamente 96 milhões de pessoas se encontravam na situação de pobreza extrema, indigência. Em termos de distribuição por situação domiciliar, 146 milhões de pessoas pobres residiam em áreas urbanas, enquanto 75 milhões residiam em áreas rurais.

Diante deste cenário, o problema da pobreza permanece na agenda, tanto das organizações internacionais ${ }^{2}$ como dos governos nacionais para a implementação de ações em diversos países da região. Neste caso, destacam-se os famosos programas de transferências de renda, que projetaram a América Latina como exemplo para o mundo neste quesito específico. Da mesma maneira, observa-se que as questões relativas à fome, pobreza e exclusão social estão presentes na agenda dos governos nacionais com a implementação de ações em diversos países da região.

Desse modo, o objetivo do artigo é analisar a estratégia adotada pelo Brasil e pela Argentina no início do século 21 para enfrentar o problema da pobreza. Para tanto, o trabalho está organizado em três seções. A primeira apresenta uma análise geral da evolução da pobreza na América Latina nos últimos trinta anos, bem como uma análise específica da evolução recente da pobreza nos dois países selecionados. A segunda seção discute as políticas públicas de enfrentamento da pobreza, destacando a emergência dos programas de transferência de renda implantados nos dois países, suas características e os principais resultados obtidos. A terceira seção apresenta as considerações finais do trabalho, enfatizando o papel desempenhado por esses programas e os desafios que ainda precisam ser enfrentados no âmbito das políticas públicas destinadas à erradicação da pobreza.

\section{Uma das consequências diretas} do pequeno crescimento econômico regional, segundo a ONU (2005), foi a redução do nível de emprego com a contrapartida no aumento da informalidade. Este duplo movimento levou a uma redução do número de pessoas cobertas pelos programas de seguridade social, obrigando os governos a ampliarem os gastos públicos na esfera social.

\section{Contexto geral da pobreza na América Latina}

A Tabela 1 apresenta a evolução percentual da pobreza, incluídos as pessoas classificadas como indigentes, para dezoito países da América Latina (Argentina, Bolívia, Brasil, Chile, Colômbia, Costa Rica, Equa- 
dor, El Salvador, Guatemala, Honduras, México, Nicarágua, Panamá, Paraguai, Peru, República Dominicana, Uruguai e Venezuela) mais o Haiti.

Tabela1 - Evolução do percentual total da pobreza na América Latina entre 1980-2010 e segundo a situação domiciliar

\begin{tabular}{|c|c|c|c|}
\hline \multirow{2}{*}{ Ano } & \multicolumn{2}{|c|}{ Percentual de pessoas pobres } & \multicolumn{2}{c|}{ Rural } \\
\hline 1980 & Total & Urbana & 59,8 \\
\hline 1990 & 40,5 & 29,8 & 65,2 \\
\hline 1999 & 48,4 & 41,4 & 64,1 \\
\hline 2002 & 43,8 & 37,1 & 62,4 \\
\hline 2005 & 43,9 & 38,3 & 59,8 \\
\hline 2007 & 39,7 & 34,0 & 53,0 \\
\hline 2008 & 34,0 & 28,8 & 52,2 \\
\hline 2009 & 33,2 & 27,4 & 54,9 \\
\hline
\end{tabular}

Fonte: CEPAL: Panorama Social deAméricaLatina(1980-2010). Elaboração própria.

As informações podem ser analisadas em três fases distintas. A primeira delas se refere à década de 1980, quando o conjunto dos países do Continente foi afetado pela crise da dívida externa que o levou a uma degradação das condições sociais. Com isso, a pobreza atingiu, ao final da década de 1980, percentuais ao redor de $48 \%$, ou seja, quase a metade da população foi considerada naquela época como sendo pobre. Sem dúvida, o avanço da pobreza pode ser explicado pela forte retração que ocorreu nas atividades econômicas na década de 1980, além dos desajustes no cenário externo onde a questão da dívida externa exerceu todas suas influências negativas sobre a maioria dos países. Com isso, a combinação de instabilidade financeira externa com o baixo crescimento econômico interno agravou a questão do emprego e da renda e deteriorou ainda mais as já precárias condições sociais. O resultado ao final da década foi uma expansão sem precedentes dos índices de pobreza.

A segunda fase se refere à década de 1990, período marcado pelas reformas políticas e econômicas em praticamente todos os países do Continente. Do ponto de vista da pobreza, nota-se uma pequena redução, até o final da década de 1990, da ordem de 4,5\%. Mesmo assim o percentual de pobreza no último ano da década de 1990 era superior ao percentual da década de 1980, demonstrando, por um lado, a gravidade do problema e, por outro, as dificuldades que os governos locais enfrentaram para reduzir de forma mais acentuada esses níveis de pobreza. Em termos absolutos, o final da última década do século 20 revelou a existência de 220 milhões de pessoas pobres na América Latina.

A terceira fase diz respeito à primeira década do século 21, período marcado por uma forte redução do percentual de pobres, especialmente a partir do ano de 2005. Isto representou uma diminuição de mais de 12 pontos percentuais em apenas uma década. Em grande medida a redução da pobreza observada durante a primeira década do século 21 pode ser creditada ao bom desempenho macroeconômico da região, uma vez que ocorreu expansão do PIB per capita na maioria dos países. Mas é importante destacar ainda que essa redução da pobreza também precisa ser discutida no âmbito das diversas políticas sociais adotadas por diversos governos, conforme veremos na seção seguinte.

\section{Evolução recente da pobreza no Brasil}

De acordo com IPEA (2009), em Junho de 2009 existiam aproximadamente 15 milhões de pessoas extremamente pobres no Brasil, sendo que no período entre 2002 e 2008 cerca de 5 milhões de pessoas deixaram esta condição social. Registre-se, todavia, que as diferenças regionais ainda permanecem em patamares elevados. 
Por exemplo, a região metropolitana de Recife apresentava a maior taxa de pobreza, enquanto que a região metropolitana de Porto Alegre detinha a menor taxa de pobreza dentre todas as áreas metropolitanas do país.

A Tabela 2 apresenta a redução percentual da pobreza no Brasil e na América Latina entre 1990 e 2007. Quando se considera a série integral nota-se que a redução da pobreza no Brasil foi superior em dois pontos percentuais comparativamente à América Latina. No entanto, quando se considera apenas os últimos seis anos (2002-2007) verifica-se que o percentual de redução é praticamente idêntico.

\section{Tabela 2 - Evolução percentual da redução da pobreza: Brasil e América Latina}

\begin{tabular}{|l|c|c|}
\hline \multirow{2}{*}{ País/Região } & \% de Pobres & Redução em Pontos \% \\
\hline Brasil & $1990 / 2002-2005 / 2007$ & $1990 / 2007-2002 / 2007$ \\
\hline América Latina & $44,9 / 38,2-34,1 / 29,0$ & $15,9-9,2$ \\
\hline \hline
\end{tabular}

Fonte: Cepal(2007)eIPEA(2008).

No período entre 2002-2007 a renda familiar per capita no Brasil cresceu a uma taxa de 5,4\% ao ano (IPEA, 2008). Mas a renda das famílias mais pobres cresceu mais se comparada à renda das famílias mais ricas: $9 \%$ e 4\%, respectivamente. Este movimento é importante quando se analisam as perspectivas da redução da pobreza através da diminuição da desigualdade de renda.

\section{Evolução recente da pobreza na Argentina}

As mudanças estruturais da economia regional durante a década de 1990 promoveram fortes restrições ao crescimento econômico, fato que desempenhou importante papel no sentido de expandir a pobreza, como foi o caso da Argentina. Além disso, outras informações revelam que o comportamento da pobreza também pode estar sendo afetado por outros fatores, especialmente pelo volume reduzido de transferências de renda aos domicílios, pela expansão dos preços relativos e pelo efeito corrosivo dos índices inflacionários. A passagem para o século 21 ampliou a deterioração das condições sociais em diversos países, destacando-se novamente o caso da Argentina que, entre o final da década de 1990 e o ano de 2002, praticamente duplicou suas taxas de pobreza, conforme pode ser observado no Gráfico 1:

\section{Gráfico 1 - Evolução dos índices de pobreza entre 1991 e 2002}

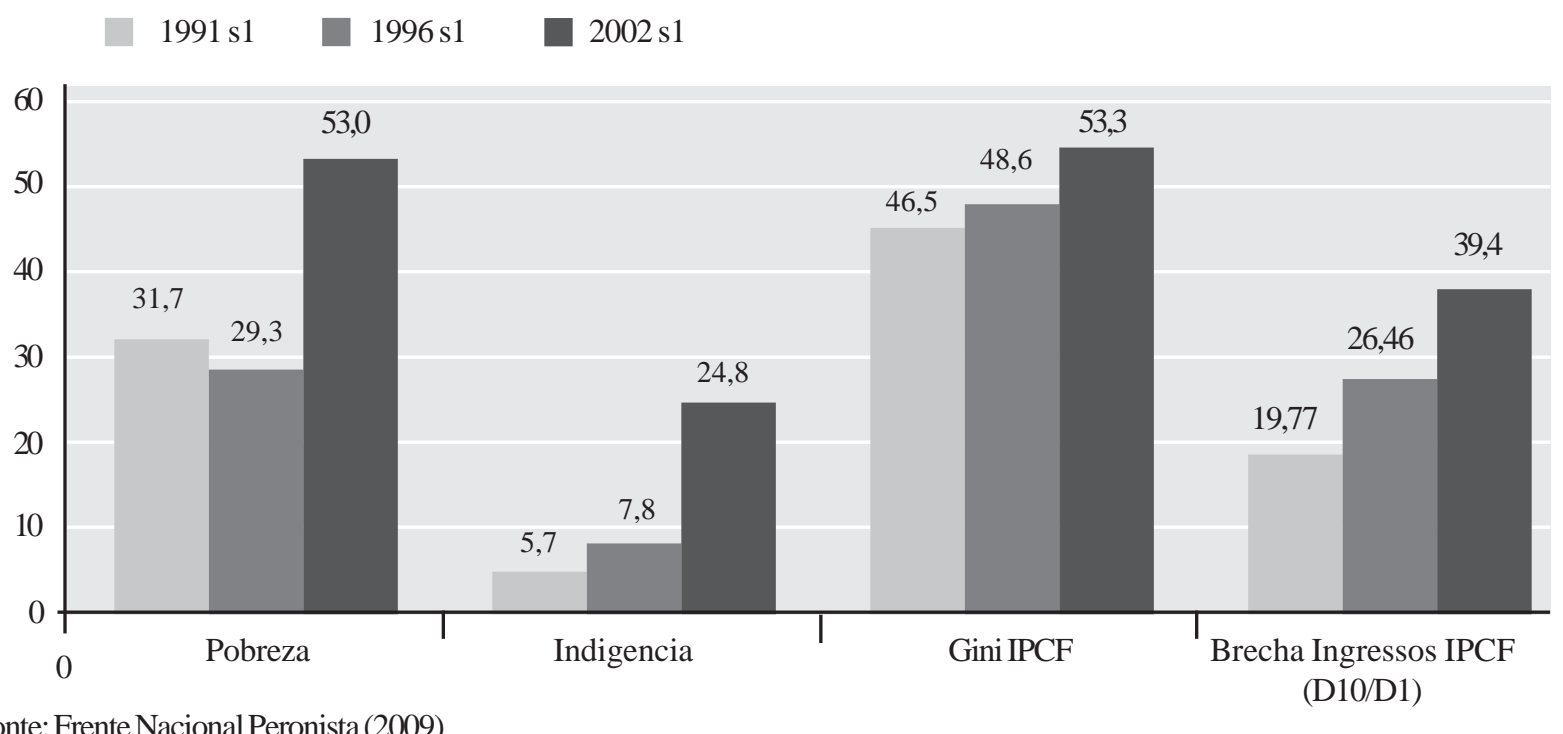

Fonte: Frente Nacional Peronista(2009) 
Assim, nota-se que tanto o programa de estabilização econômica como as reformas estruturais adotadas pela Argentina durante a década de 1990 geraram um clima ilusório de estabilidade econômica que acabou ruindo antes mesmo do final daquele período. Com isso, a Argentina ingressou no século 21 com uma elevação expressiva dos indicadores de pobreza e exclusão social.

\section{Políticas públicas de enfrentamento da pobreza no Brasil e na Argentina: estratégia comum nos dois países}

No âmbito dos governos dos países da América Latina, verifica-se que ao longo das últimas décadas foram implementados diversos programas de transferência de renda com o objetivo de combater a pobreza através da visão da focalização das ações de política pública. Esta visão foi fortemente influenciada pelas experiências pioneiras realizadas em países como Brasil e México, ainda nos anos de 1996 e 1997, respectivamente.

Os Programas de Transferência Condicionada de Renda (Conditional Cash Transfer Programs, CCTP) destinam mensalmente certa quantia monetária para as famílias classificadas como pobres ou extremamente pobres, tendo por objetivos melhorar as condições de saúde e de educação desta parte da população excluída socialmente do mercado de bens e serviços. Para tanto, são exigidas certas responsabilidades dos beneficiários relativas aos cronogramas de execução de cada programa. De um modo geral, esses programas geralmente são políticas focalizadas a partir de dados e informações socioeconômicas sobre as famílias e domicílios, destinando recursos monetários diretamente aos beneficiários. Há, todavia, situações que incluem, além de recursos financeiros, doações de alimentos e complementos nutricionais. A maioria dessas políticas estabelecem que os beneficiários devem cumprir certas tarefas para continuar recebendo os benefícios a que têm direito. Este tipo de política social está fortemente condicionado pela ideia da focalização, a qual tem como pressuposto as análises de custo-impacto. Por isso, as ações destinam-se preferencialmente aos grupos mais vulneráveis da população visando, por um lado, gerar compensações sociais devido aos desajustes criados pelo modelo de desenvolvimento econômico (desemprego, queda da renda, exclusão etc.) e, por outro, proteger minimamente aquela parcela de cidadãos submetidos ao círculo vicioso da pobreza e da desigualdade.

Em síntese, considerando as diretrizes e ações das políticas e programas destinados ao combate à pobreza em curso em um grande número de países da América Latina a partir da década de 1990, é possível identificar e construir uma tipologia de políticas sociais de combate à pobreza a partir de quatro grupos básicos 3 :

(a) Políticas e programas de transferências sociais: incluídos os programas de transferência de renda (condicionados e não condicionados), além de outros benefícios sociais (aposentadorias, pensões etc.);

(b) Programas assistenciais emergenciais: ações sociais emergenciais como distribuição de cestas básicas de alimentos, auxílio social nas redes de saúde, auxílio aos desempregados etc.;

(c) Políticas estruturais de combate à pobreza: destacando-se os programas públicos de incentivo ao emprego, projetos produtivos, microcrédito e estímulo ao auto emprego, apoio à construção de redes de infraestrutura social básica, fortalecimento de organizações comunitárias etc.;

(d) Políticas destinadas aos grupos sociais específicos: destacam-se os programas destinados ao atendimento focalizado nas causas da pobreza e apoio às crianças, mulheres nutrizes e chefes de família, aos jovens, grupos étnicos específicos, grupos portadores de deficiência etc.

\section{O caso brasileiro: dos primeiros programas de transferência de renda ao Bolsa Família}

As primeiras experiências com programas de transferência de renda no Brasil precederam os programas do Governo Federal e ocorreram inicialmente apenas em algumas localidades (IPEA 2008; CUNHA; PINTO, 2008; ROCHA, 2008; SOARES; SÁTYRO, 2009). Essas experiências pioneiras, especialmente nos municípios de Campinas (SP) e de Ribeirão Preto (SP), estavam mais assentadas na filosofia de garantia de uma Renda Básica de Cidadania (RBC), a qual se constitui, segundo seus principais defensores ${ }^{4}$, em um dos caminhos mais eficientes para se erradicar a pobreza.

Posteriormente, inspirados nas experiências pioneiras de Campinas, de Ribeirão Preto e do Distrito Federal, esses programas passaram a se proliferar por diversas regiões do país (LAVINAS, 1998). No entanto, este processo ocorreu de forma atabalhoada e sem as condições técnicas operacionais e financeiras que a implementação deste tipo de política exigia (ROCHA, 2008), por isso muitas dessas experiências foram sendo abandonadas nos anos seguintes.

Na esfera do Governo Federal os primeiros programas de transferência de renda surgiram em 1997 no âmbito do programa Comunidade Solidária ${ }^{5}$, que procurou promover reformas profundas na política social 
(saúde, educação, previdência, habitação e assistência social) visando focalizar o gasto público e aumentar sua eficiência em um ambiente de ajustes macroeconômicos que se opunham à expansão do gasto governamental na área social.

Assim, começaram a funcionar em 2001, ainda no Governo FHC, os programas: Bolsa Escola, vinculado ao Ministério da Educação, o Bolsa Alimentação, vinculado ao Ministério da Saúde, e o Auxílio Gás, vinculado ao Ministério de Minas e Energia ${ }^{6}$. Os dois primeiros programas tinham a seguintes contrapartidas: crianças entre 6 a 15 anos deviam ter frequência mínima de 85\% nas escolas, manterem as vacinações atualizadas, e as mães deviam frequentar os postos de saúde fazendo todos os exames e tratamentos necessários.

No início do Governo Lula, março de 2003, foi criado no âmbito do Ministério de Desenvolvimento Social e de Combate à Fome, o Cartão Alimentação, que correspondia ao programa cupom de alimentos na versão original do Programa Fome Zero (PFZ), também com o objetivo de transferir renda para parcelas da população que se encontrava em estado de insegurança alimentar e nutricional. Com isso, no final de 2003, a gestão desse conjunto de programas de transferência de renda estava caótica, uma vez que não havia coordenação política entre os diferentes órgãos governamentais e a comunicação entre os programas praticamente inexistia.

Visando superar esses problemas, em outubro de 2003, foi criado o programa Bolsa Família, com o objetivo de unificar todos os programas sociais de transferência de renda já existentes anteriormente (Bolsa Escola, Bolsa Alimentação, Cartão Alimentação e Auxílio Gás). Além do objetivo geral, o programa pretendia dar maior agilidade ao processo de liberação mensal dos recursos financeiros às famílias necessitadas, bem como reduzir os entraves burocráticos e facilitar o sistema de controle de recursos visando aumentar sua transparência junto à sociedade. De uma maneira geral, o programa Bolsa Família articula-se a partir de três aspectos básicos: ampliação dos serviços de saúde, educação e nutrição, através dos mecanismos de condicionalidades; integração dos programas de transferência renda com os demais programas de assistência e proteção social; e busca da superação direta da pobreza através da focalização das transferências monetárias decorrentes das ações governamentais.

A condicionalidade é determinada ao responsável pela família e diz respeito aos seguintes itens: manter as crianças em idade escolar frequentando as escolas; manter o sistema de vacinação das crianças atualizado; mulheres grávidas devem fazer todos os exames recomendados; e promover a alfabetização nos casos em que há analfabetos adultos entre os membros da família beneficiada.

No âmbito do Governo Federal a gestão do programa está sob responsabilidade do Ministério do Desenvolvimento Social e Combate à Fome (MDS) que, por meio da Secretaria Nacional de Renda de Cidadania (SENARC), define as regras de funcionamento do programa, estabelece os valores dos benefícios, bem como articula as parcerias entre estados e municípios.

\section{O caso argentino: dos primeiros programas ao Asignación Universal por Hijo}

Enquadrados dentro das características de programas de transferência de renda, nota-se que inicialmente a Argentina implantou dois programas: Jefes de Hogar e Plan Famílias. O programa de transferência de renda Jefes de Hogar foi criado em 2001 tendo como objetivo apoiar as famílias que se encontravam em situação de pobreza, visando melhorar a inserção profissional e o nível de emprego. Era um programa dirigido especialmente aos chefes de famílias desempregados, homens ou mulheres, e com pelo menos uma criança de até 18 anos de idade, com o objetivo de assegurar a permanência dessas crianças nas escolas, além de fazer o controle da saúde básica. O programa também contemplava as famílias cujas mulheres estejam grávidas e os maridos estivessem desempregados. Além disso, o programa também procurava incorporar a população desempregada em projetos comunitários que gerassem impactos sobre os níveis de ocupação da mão de obra.

O segundo programa de transferência de renda, Plan Familias, foi criado em 2004 com o objetivo de promover valores que dão coesão, articulam e tornam possível a vida em família e na sociedade de forma harmoniosa, tendo como parâmetro uma política social de integração. Para tanto, buscava-se promover, através desse programa, o respeito aos direitos humanos, a integração dos desfavorecidos e a igualdade de oportunidades para todos os membros das famílias (REPETTO; DAL MAZETTO, 2011). O Plan Familias compreendia quatro subprogramas: famílias pela inclusão social, centros integrados comunitários, comissão nacional de pensões assistenciais e o tema do desenvolvimento social e sanitário. Porém, as transferências monetárias ocorriam apenas no âmbito do primeiro subprograma. As ações monetárias correspondiam à transferência mensal de rendas às famílias pobres, cujo valor variava de acordo com a quantidade de filhos menores de 18 anos existentes em cada domicílio. Em 2005, por exemplo, famílias com apenas um filho nesta condição recebiam 155 pesos, enquanto famílias com seis ou mais filhos recebiam 305 pesos. Além disso, destinava-se uma bolsa mensal de 50 pesos para jovens e adultos continuarem seus estudos e suas formações profissionais. 
Este programa, na verdade, procurava coordenar os esforços e os recursos do Governo Federal junto às províncias e às municipalidades no sentido de proteger as famílias vulneráveis e extremamente pobres, visando integrá-las ao contexto social do país.

Diante das críticas às iniciativas existentes, a presidente Cristina Kirchner implantou, no mês de Novembro de 2009, via Decreto, o programa Asignación Universal por Hijo (AUH), cuja finalidade é atender as famílias pobres desempregadas e/ou no mercado informal que têm filhos em idade escolar, bem como as famílias que eram atendidas pelos planos antes mencionados que passaram a fazer parte do AUH a partir de 2010. Com isso, em dezembro de 2009 , aproximadamente $50 \%$ dos beneficiários eram decorrentes dos demais programas do sistema de proteção social, ou seja, pode-se dizer que o AUH é um programa que unifica diversos outros com a mesma finalidade, fato este que repete a experiência do programa Bolsa Família no Brasil (ANSeS, 2010).

Do ponto de vista das regras de participação no programa, serão pagos benefícios às famílias com crianças e adolescentes menores de 18 anos ou com membros incapacitados para o exercício do trabalho sem limite de idade, os quais pertencem às famílias cujos pais estejam desempregados e/ou exercendo atividades na economia informal, sendo que especificamente para os desempregados, a regra é que este não esteja recebendo qualquer remuneração oriunda do programa seguro desemprego (MAURICIO; VÁZQUES, 2014).

\section{Principais resultados apresentados pelos dois países}

No caso brasileiro é amplamente conhecido que a trajetória histórica da pobreza está associada aos níveis de desigualdade da renda. Assim, tomando como referência o critério da renda, Rocha (2008) mostrou que em 2004 mais de 50\% das famílias de baixa renda detinham apenas 15\% da renda total do país. Esta é uma das razões que explicam o fato do Brasil continuar a apresentar um dos maiores coeficientes do Índice de Gini em todo o mundo. Em função disso, a autora defende que transferências de renda, mesmo com valores baixos como é o caso das transferências do Bolsa Família, têm impactos mensuráveis sobre a pobreza e desigualdade da distribuição de renda.

Do ponto de vista da contribuição dos programas de transferência sobre a redução na desigualdade de renda, notam-se algumas controvérsias entre estudos, especialmente no que diz respeito ao percentual dos impactos. Levando-se em consideração que a renda total das famílias é composta por rendimentos do trabalho, que são preponderantes, e por outras rendas oriundas de benefícios da Previdência Social e dos programas de Assistência Social, como o Bolsa Família, um estudo do IPEA (2009) revelou que a renda do trabalho foi responsável por aproximadamente $65 \%$ de toda a queda do Coeficiente de Gini verificada entre 2001 e 2008, enquanto que os todos os benefícios sociais governamentais responderam por cerca de $34 \%$.

Outro estudo (SOARES, 2006) estimou que a renda do trabalho, entre 2001 e 2004, foi responsável por $68 \%$ da redução da desigualdade na renda verificada no período, enquanto os outros rendimentos responderam por $27 \%$ da redução da desigualdade ${ }^{8}$. Após mensurar os efeitos das transferências da Previdência Social e dos aluguéis, Soares estima que o programa Bolsa Família foi responsável por aproximadamente 12\% da redução no nível de renda observada no período considerado.

Barros et all. (2006), analisando o comportamento das transferências públicas entre 2001 e 2004, concluíram que as mesmas foram responsáveis por $33 \%$ da redução na concentração de renda, sugerindo que este tipo de ação está tendo uma importância crescente no combate à desigualdade de renda no país. Ao decompor a participação de cada um dos programas de transferência pública concluiu-se que o Bolsa Família respondeu por $11 \%$ do total da redução observada no período considerado.

No caso da Argentina, como o programa AUH ainda é relativamente recente, praticamente inexistem análises de impactos, da mesma forma que as verificadas para o Brasil, isto porque o programa Bolsa Família já completou mais de dez anos, enquanto o programa AUH tinha menos de cinco anos. Mesmo assim, foi possível se observar que no primeiro ano de existência, segundo a ANSeS (2010), o programa atingiu 1.927.000 de domicílios e atendeu 3.684 crianças e adolescentes de famílias pobres, disponibilizando um valor médio de \$ 338 por pessoas. Do ponto de vista dos domicílios, verifica-se que $46 \%$ do total atendido teve apenas um filho beneficiado, enquanto $28 \%$ dos domicílios atendidos tiveram dois filhos beneficiados e $15 \%$ tiveram três filhos atendidos. Já a origem desses beneficiários é um indicador importante, uma vez que $62 \%$ eram novos, ou seja, filhos de famílias que nunca tinham recebido nenhum benefício de programas sociais do Governo Federal.

Quanto à participação do gasto do AUH no gasto total, informações extra oficiais revelam que este programa representava no ano de 2010 apenas $0,58 \%$ do total do PIB do país. Isto tem possibilitado um benefício médio mensal de aproximadamente U\$55,00 por filho de cada família pobre, valor que fica um pouco abaixo do similar Bolsa Família no Brasil, cujos benefícios no mesmo ano atingiram um valor médio de U\$ 65,00 (MAURICIO; VÁZQUES, 2014; ANSeS, 2010). 
Em termos dos impactos do programa de transferência de renda sobre a pobreza, estudos preliminares revelaram que no primeiro ano o AUH reduziu a pobreza geral em 13\% e a pobreza extrema, também chamada de indigência, em 55\%. Com isso, algumas fontes indicam que o programa tem contribuído para que o nível de desigualdade se situasse no patamar mais baixo desde o ano de 1986, o que situa a Argentina entre os países com os menores níveis de desigualdade de renda na América Latina (ROFMAN; OLIVERI, 2011).

Mesmo com essas informações oficiais e extraoficiais bastante positivas sobre os impactos do AUH na Argentina, recomenda-se certa cautela na análise das mesmas, tendo em vista o breve tempo de execução do referido programa, bem como a ausência de análises efetivas de mensuração de impactos sobre os níveis de pobreza no país.

\section{Considerações finais}

O processo de redução da pobreza que ocorreu, tanto no Brasil como na Argentina, na primeira década do século 21, foi fortemente marcado: pela reativação das atividades econômicas que provocaram elevação das taxas de crescimento; pela recuperação do poder de compra dos salários, especialmente do salário mínimo; e pela expansão dos programas governamentais de transferência de renda. Esses fatores, em conjunto, desempenharam importante papel no combate à pobreza em ambos os casos considerados. Assim, a combinação de crescimento econômico com redução da desigualdade de renda foi decisiva para reduzir as taxas de pobreza nos dois países a partir dos primeiros anos do presente século.

Particularmente, em termos dos programas governamentais de transferência de renda às famílias em situação de vulnerabilidade social, deve-se registrar que ações neste sentido, tanto através de subsídios como de transferências monetárias diretas, já faziam parte da agenda de programas sociais de combate à pobreza, tanto no Brasil como na Argentina. A novidade é que esses programas introduziram mecanismos que passaram a condicionar as referidas transferências ao cumprimento, por parte dos beneficiários, de um conjunto de atividades vinculadas particularmente às áreas de saúde, educação e nutrição com o objetivo de melhorar os padrões sociais desta parcela da sociedade que vive em constante ameaça.

Este tipo de política social está fortemente orientado pela ideia da focalização das ações dos Estados nacionais, a qual tem como pressuposto as análises de custo-impacto. Por isso, as ações destinam-se preferencialmente aos grupos mais vulneráveis da população visando, por um lado, gerar compensações sociais devido aos desajustes criados pelo modelo de desenvolvimento econômico (desemprego, queda da renda, exclusão etc.) e, por outro, proteger minimamente aquela parcela de cidadãos submetidos ao círculo vicioso da pobreza e da desigualdade. Estes fatos lançam questionamentos sobre as reais possibilidades dos programas condicionados de transferência de renda de alcançarem um seus principais objetivos, ou seja, romper com o ciclo intergeracional da pobreza. Em grande medida, esse questionamento decorre do baixo nível de conexão entre os programas de transferências monetárias e as demais políticas de assistência social em curso. Em parte, essa desconexão tem origem na própria formulação dos CTP, uma vez que os mesmos pressupõem a falência das políticas de assistência social tradicionais, colocando-se como alternativa e/ou como políticas que seriam capazes de substituir os sistemas tradicionais de proteção social.

Neste sentido, recolocamos que o tema da pobreza, por ser um fenômeno complexo e multidimensional, não pode ser tratado apenas como um problema de insuficiência de renda e nem seu combate ficar restrito às transferências monetárias. As políticas de combate à pobreza não podem estar dissociadas de um projeto que busque a construção de uma rede de proteção social através da universalização das políticas distributivas como forma de promover um desenvolvimento mais igualitário. Do contrário, muitos programas em curso poderão assumir um papel meramente paliativo ao não procurar atacar as causas estruturais da pobreza de longo prazo.

\section{Referências}

ADMINISTRACION NACIONAL DE LA SEGURID SOCIAL (ANSeS). Primer aniversario. Buenos Aires, Octubre 2010. BARROS, R. P. et al. Desigualdade de renda no Brasil: uma análise da queda recente. Brasilia: IPEA, 20006, v.1, 446p. COMISIÓN ECONÓMICA PARA AMÉRICA LATINA Y EL CARIBE. Hambre y cohesión social en América Latina: como reverter la relación entre inequidad y desnutrición. Santiago de Chile: CEPAL, 2005, 37p. . Anuario estadístico de América Latina y de Caribe. Santiago de Chile: CEPAL, 2007.

COMISSÃO ECONÔMICA PARA A AMÉRICA LATINA E CARIBE. Panorama Social de América Latina. Santiago do Chile: CEPAL (diversos anos). 
CUNHA, R. E.; CÂMARA PINTO, B.H. O programa bolsa família como estratégia para redução da pobreza e da desigualdade no Brasil. Buenos Aires (Arg.): Anais do XIII Congresso Internacional del CLAD, 2008.

FRENTE NACIONAL PERONISTA. Buenos Aires: Tiempo Argentino, 2009.

IPEA. Pobreza e Mudança Social. Comunicado da Presidência, n. 9, set. 2008.

PNAD 2008: primeiras análises. Comunicado da Presidência, n. 30, set. 2009. 2009

Desigualdade e pobreza no Brasil metropolitano durante a crise internacional. Comunicado da Presidência, n.25, Agosto de

LAVINAS, L. Programas de garantia de renda mínima. Rio de Janeiro: IPEA, 1998 (Texto para Discussão n. 596).

MAURICIO, R.; VÁZQUEZ, G. Argentina: efectos del programa Asignación Universal por hijo en el comportamiento laboral de los adultos. Santiago de Chile (CH): CEPAL, 2014.

ORGANIZACIÓN DE LAS NACIONES UNIDAS. Programa de lucha contra el hambre: enfoque de doble componente para reducción del hambre y prioridades para actuación a nivel nacional e internacional. Roma: Naciones Unidas/FAO.2005 (d).

REPETTO, F.; DAL MAZETTO, F. P. Protección Social em la Argentina. Santiago: CEPAL, 2011 (Série Políticas Sociais, n. 174).

ROCHA, S. Transferências de renda federais: focalização e impactos sobre pobre e desigualdade. In: Revista de Economia Contemporânea, v.12, n.1, p.67-96, Jan./Abr. 2008.

ROFMAN, R.; OLIVERI, M. Las políticas de protección social y sua impacto em la distribuição del ingresso em Argentina. Washington, DC: Banco Mundial (Documentos de trabajo n.6), 2011

SOARES, S. Distribuição da renda no Brasil de 1976 a 2004 com ênfase no período entre 2001 e 2004. Rio de Janeiro: IPEA(Texto para Discussão, 1.166), 2006.

SOARES, S.; SÁTYRO, N. O programa Bolsa Família: desenho institucional, impactos e possibilidades futuras. IPEA (Texto para Discussão n.1424), 2009.

SUPLICY. E. M. Renda Básica de Cidadania: a saída é pela porta. São Paulo: Editora Cortez, 2002.

\section{Notas}

1 AComissão Econômica para a América Latina e o Caribe (CEPAL) utiliza Linha de Pobreza e de Pobreza Extrema (Indigência), no lugar da linha one dollar a day desenvolvida pelo Banco Mundial, para dimensionar a pobreza no Continente Latino-Americano por considerar que este método representa melhor as condições sociais em todos os países da região.

2 A ONU lançou a meta do Milênio no ano de 2000, a qual consiste em erradicar a pobreza pela metade até 2015. Já a FAO lançou recentemente a iniciativa América Latina Sem Fome em 2025, com objetivo de erradicar a fome no continente até aquela data.

3 Registre-se que certos programas podem estar associados a mais de um grupo de políticas.

4 No Brasil, o Senador Eduardo Suplicy (PT)é o principal expoente desta corrente, tendo escrito um livro clássico sobre o assunto: Renda Básica de Cidadania: a saída é pela porta (2002). Além disso, o Senador conseguiu aprovar, em 2004, um projeto de sua autoria que instituiu no país a RBC.

5 O programa Comunidade Solidária era o nome do programa guarda-chuva que englobava todas as ações do Governo Fernando Henrique Cardoso na área social. Uma correlação pode ser feita ao programa Fome Zero, do Governo Lula, em que o Bolsa Família é uma das ações.

6 Na verdade, o Auxílio Gás era apenas um benefício financeiro às famílias com renda inferior a meio salário mínimo, não tendo nenhuma condicionalidade.

7 Como a Previdência Social responde por cerca de 70\% e $80 \%$ do total dessas transferências, pode-se estimar que a contribuição do programa Bolsa Família na redução da desigualdade de renda se situa em tornode $10 \%$.

8 Fazem parte da rubrica "outros rendimentos", rendas de transferências governamentais, pagamentos de juros e dividendos e rendimentos de aluguéis.

\section{Lauro Mattei}

1.mattei@ufsc.br

Doutorado em Ciência Econômica pela Universidade Estadual de Campinas

Professor no curso de Graduação em Ciências Econômicas e no Programa de Pós-Graduação de Administração da Universidade Federal de Santa Catarina.

\section{UFSC -}

Campus Universitário Reitor João David Ferreira Lima

Bairro Trindade

Florianópolis - Santa Catarina

CEP: 88010-970 